\title{
Programa de Erradicação do Trabalho Infantil: Ações Extensionistas e Protagonismo
}

The Child Labour Eradication Program:

Extensionist Actions And

Youth Empowerment Programa De Erradicación Del Trabajo Infantil: Acciones Extensionistas Y Protagonismo

Maria de Fátima Pereira Alberto, Romanan Silva Borges, Manuella Castelo Branco Pessoa, Juliana Mendes Lopes de Sousa, Pedro Felipe Moura de Araújo, Rodrigo de Oliveira Feitosa Vaz, Felipe Medeiros de Farias \& Leonardo José de Alencar Mendes

Universidade Federal da Paraíba
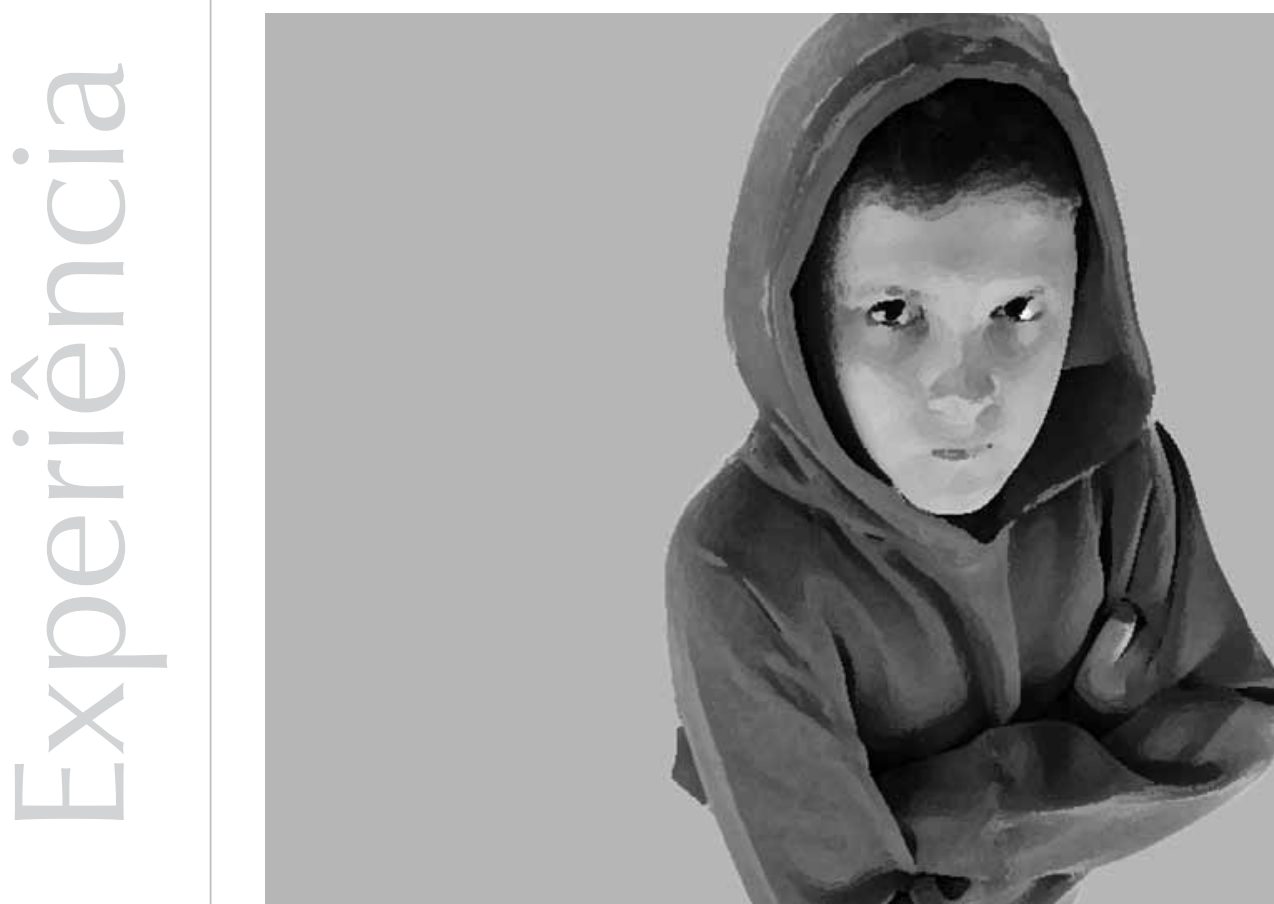
Resumo: Este artigo apresenta uma experiência de extensão desenvolvida por estudantes e professores de Psicologia nos Núcleos do Programa de Erradicação do Trabalho Infantil (PETI) da cidade de João Pessoa. A extensão objetivava desnaturalizar o trabalho infantil, contribuir para a formação da cidadania, desenvolver o protagonismo e formar profissionais em Psicologia social. O PETI é um programa do Governo Federal que objetiva retirar crianças e adolescentes de 7 a 15 anos e 11 meses de idade do trabalho perigoso, penoso, insalubre ou degradante, e fundamenta-se nos aportes teóricos da história da criança, dos direitos das crianças e adolescentes, do protagonismo juvenil e da educação popular. A metodologia visa à construção conjunta considerando as experiências dos diferentes atores. Utilizamos oficinas de literatura, escrita, música, filmes, fotografia, gibis, desenhos, Estatuto da Criança e do Adolescente, conversas em círculos, jogos e brincadeiras. A experiência conduziu-nos para aspectos que nem mesmo estavam entre os objetivos do trabalho. Percebemos que as crianças e os adolescentes do PETI não se veem como sujeitos de direitos, naturalizam a violência e não acreditam em mudanças, mas apresentam lampejos de resistência, de participação e de ações coletivas.

Palavras-chave: Trabalho infantil. Direitos da criança. Empoderamento. Psicologia social.

Abstract: This article presents an extension experience developed by psychology students and professors on the Núcleos do Programa de Erradicação do Trabalho Infantil (PETI) in João Pessoa. The extension had the objective to denaturalize the child labor, contributing to the citizen's constitution, developing the empowerment and constituting social-psychology professionals. PETI is a federal government program that aims at saving children and adolescents from seven to fifteen years and eleven months old from dangerous, painful, insalubrious or degrading labour. This research is based on the theories about child history, children and adolescents' rights, youth empowerment and popular education. The methodology was based on collective construction, considering the different subjects' experiences. We worked with literature workshops, writing, music, movies, photography, comic books, drawings, The Child and Adolescent Statute, conversation circles, sports and games. The experience led us to aspects that were not even among the objectives of the work. We realize that PETI's children and adolescents don't see themselves as citizens of rights, naturalize violence and don't believe in changes. Still, they present sparkles of resistance, participation and collective actions.

Keywords: Child labour. Children rights. Empowerment. Social psychology.

Resumen: Este artículo presenta una experiencia de extensión desarrollada por estudiantes y profesores de Psicología en los Núcleos del Programa de Erradicación del Trabajo Infantil (PETI) de la ciudad de João Pessoa. La extensión objetivaba desnaturalizar el trabajo infantil, contribuir para la formación de la ciudadanía, desarrollar el protagonismo y formar profesionales en Psicología social. El PETI es un programa del Gobierno Federal que tiene como objetivo apartar a niños y adolescentes entre 07 años y 15 años y 11 meses de edad del trabajo peligroso, penoso, insalubre o degradante, y se fundamenta en los aportes teóricos de la historia del niño, de los derechos del niños y de los adolescentes, del protagonismo juvenil y de la educación popular. La metodología tiene como objetivo la construcción conjunta considerando las experiencias de los diferentes actores. Hemos utilizado talleres de literatura, escrita, música, películas, fotografías, cómics, dibujos, Estatuto del Niño y del Adolescente, conversaciones en círculos, juegos y jugueteos. La experiencia nos ha conducido a aspectos que ni siquiera se encontraban entre los objetivos del trabajo. Nos hemos dado cuenta de que los niños y los adolescentes del PETI no se ven como sujeto de derechos, naturalizan a la violencia y no creen en cambios, sino que presentan momentos de resistencia, de participación y de acciones colectivas.

Palabras clave: Trabajo infantil. Derecho del niño. Adquisición de poder. Psicología social.

Este texto objetiva apresentar uma experiência de extensão realizada em dois núcleos do Programa de Erradicação do Trabalho Infantil (PETI), denominados, para efeito deste artigo, Núcleo 1 e Núcleo 2. Esse formato de extensão pretende dar continuidade a uma proposta de trabalho que vem sendo desenvolvida desde 2001 pela Universidade Federal da Paraíba através do Núcleo de Pesquisas e Estudos sobre o Desenvolvimento da Infância e Adolescência (NUPEDIA). O foco tem sido o trabalho infantil, com atuação via pesquisa e via extensão.

Ao longo de dez anos de atuação do NUPEDIA, o foco do trabalho foi sendo deslocado, e passou a abarcar a extensão e a pesquisa. Entre 2001 e 2003, o foco das ações foi a formação de agentes de direitos humanos para atuarem no combate ao trabalho infantil; 
de 2003 a 2004, o foco foi a pesquisa nas instituições onde trabalham os referidos agentes; em 2004, o foco foi a extensão com as famílias através de um balcão de direitos; em 2005, deu-se continuidade à formação dos agentes de direitos humanos, e, de 2008 a 2010, o foco das atividades tem sido as crianças e os adolescentes atendidos nas atividades socioeducativas, antiga Jornada Ampliada do PETI, através do Programa de Bolsas de Extensão (PROBEX).

As pesquisas possibilitaram identificar, durante os anos 2001 e 2005, o despreparo ou a inexistência de formação e capacitação de pessoal para atuar nessa área, e desenvolvemos, através de atividades de extensão, um know how em termos da formação de profissionais. Todavia, o conhecimento acumulado vinha sendo aplicado a profissionais que trabalhavam em instituições públicas e em organizações não governamentais, mas que atuavam em atividades indiretas de combate ao trabalho infantil e de defesa do adolescente trabalhador.

Outra via de acumulação de conhecimento foi a pesquisa. Várias delas foram realizadas com crianças trabalhadoras em várias atividades, entre as quais vendedores(as) nas ruas, olheiros de carro, pescadores de marisco e catadores de siri-mole, engraxates, catadores de lixo, ajudantes de mercadinho, feirantes, fretistas, limpadores de túmulos em cemitério, entregadores de botijões de gás de cozinha, cultura do abacaxi, cultura da cana-de-açúcar, cultura da acerola, trabalhadoras domésticos(as), meninas inseridas na exploração sexual comercial e malabares, além de pesquisas sobre o PETI.

Essa produção revelou vários aspectos, entre eles, a compreensão de que as políticas públicas de combate ao trabalho infantil não conseguiam viabilizar a sua erradicação (Domingos, Silva, \& Teixeira, 2003; Teixeira,
Silva, \& Melo, 2003). Desse modo, os números oscilavam entre a diminuição, em um ano, e o aumento, no outro, como mostram os dados da PNAD. O número de crianças e adolescentes que trabalham, no Brasil, na faixa de 5 a 17 anos, em 2003, era de 5,1 milhões; em 2004, 5,3 milhões; em 2005, 5,9 milhões; em 2006, 5,3 milhões, e, em 2007, 4,8 milhões (OIT, 2008).

Outra constatação que veio corroborar a produção na área foi que o PETI diminuía, mas não erradicava o trabalho infantil (OIT, 2001; Buonfiglio, 2004; UNICEF, 2004; IPEA, 2008), e que havia se descaracterizado como política de combate (Rua, 2007). Às vezes, a permanência das crianças e dos adolescentes no PETI estendia-se por anos a fio, mas sem oportunizar perspectivas de futuro (Pinheiro, 2008). Constatou-se também que os educadores não tinham formação específica (Dantas, 2006) e que os psicólogos que atuam nas instituições que desenvolvem o PETI não recebem na universidade o conhecimento para nele atuar (Alberto, Almeida, Dória, Guedes, Sousa, \& França, 2008).

Considerando-se todos esses aspectos, de 2008 a 2010, tem sido desenvolvida por estudantes e professores uma experiência de extensão. Dessa feita, porém, a atuação voltouse para as crianças e os adolescentes, e teve como principal objetivo a sua potencialização, e, como objetivos específicos, desnaturalizar o trabalho infantil, contribuir para a formação da cidadania de crianças e adolescentes egressas do trabalho infantil, desenvolver junto a eles uma cultura de protagonismo e formar futuros psicólogos a partir da atuação da Psicologia social.

\section{As ferramentas teóricas}

Embora, ao longo da história do Brasil, diversas leis tentem proibir o trabalho infantil, apenas nos anos 90, com a criação 
do Estatuto da Criança e do Adolescente - ECA, é que a erradicação e a prevenção assumem contornos práticos e dimensões internacionais (Acción, 1996; Alberto, 2002). Desde 1992, o Brasil integra a rede de países atingidos pelo Programa de Erradicação do Trabalho Infantil (IPEC) da OIT. Em 1996, foi realizado, sob a responsabilidade do Ministério do Trabalho, um diagnóstico preliminar do trabalho infantil. A partir dessa data, articuladas pelo Fórum Nacional de Prevenção e Erradicação do Trabalho Infantil, organizações governamentais e não governamentais experimentaram uma metodologia de trabalho conjunto, do qual originou o Programa de Ações Integradas - PAI, posteriormente, PETI. As primeiras experiências foram desenvolvidas nas minas de carvão no Mato Grosso do Sul, nos canaviais de Pernambuco e na região sisaleira da Bahia (Campos, 1999).

O PETI é um programa do Governo Federal que tem como objetivo retirar crianças e adolescentes de 7 a 15 anos e 11 meses de idade do trabalho considerado perigoso, penoso, insalubre ou degradante, ou seja, que coloca em risco sua saúde e seu desenvolvimento. O programa tenta cumprir o que determinam a Constituição Federal, o ECA e a Lei Orgânica da Assistência Social - LOAS: o amparo e a proteção às famílias, crianças e adolescentes em situação de risco.

O objetivo do PETI, além da erradicação do trabalho infantil, é o retorno, a permanência e o bom desempenho de crianças e adolescentes na escola, fomentar, incentivar e ampliar o universo de conhecimento desses cidadãos em processo de desenvolvimento através de atividades esportivas, culturais e artísticas, e o apoio, a orientação, a capacitação e a geração de renda junto às famílias, visando à devolução da responsabilidade na manutenção do grupo familiar. São beneficiários do programa crianças e adolescentes oriundos de famílias com renda per capita de até meio salário mínimo (Brasil, 2002). As ações do PETI com as crianças e os adolescentes materializamse no contra-turno escolar. Funcionam em núcleos por um período de quatro horas, de segunda a sexta-feira, sob a orientação de monitores.

Em 2004, o Programa Nacional de Renda Mínima, vinculado ao Ministério da Educação -Bolsa Escola, e outros programas considerados remanescentes foram unificados pela Lei no 10.836, que criou o Programa Bolsa Família, destinado aos procedimentos de gestão e de execução das ações de superação da pobreza. Em 28 de dezembro de 2005, o Ministério do Desenvolvimento Social - MDS (2005), através da portaria n.. 666, integrou o PETI ao Programa Bolsa Família. Os objetivos eram aprimorar e racionalizar os processos de gestão e unificar o Cadastramento Único de Programas Sociais do Governo Federal (Brasil, 2005).

As análises feitas por Rua, em pesquisa realizada para o Fórum Nacional de Prevenção e Erradicação do Trabalho Infantil (FNPETI), e as do Instituto de Pesquisa Econômica Aplicada - IPEA (2008), em análise dos dados da Pesquisa Nacional de Amostra por Domicílio (PNAD), avaliam que a integração dos programas descaracterizou o PETI como política de combate ao trabalho infantil. A unificação confirma, entre outros aspectos, a omissão dos pais ou responsáveis ante o não interesse de que as crianças e adolescentes deixem de trabalhar, a não avaliação do desempenho escolar e a precariedade do controle exercido por gestores dessa política sobre a oferta e a frequência das ações socioeducativas e de convivência no programa, resultado da ausência de uma definição precisa do que devem ser tais ações.

Análises nesse sentido apontavam que, apesar de o PETI mostrar à sociedade que sua atuação é positiva por contribuir com 
Outro ponto importante é a falta de proposta pedagógica de referência para o desenvolvimento das atividades da jornada ampliada, além dos espaços físicos inadequados e insuficientes, e a desarticulação entre a atuação da rede regular de ensino com a jornada ampliada, o que não contribui para o processo de aprendizagem das crianças e dos adolescentes (UNICEF, 2004; OIT, 2001). a diminuição do trabalho infanto-juvenil, o programa não coopera para a erradicação nem para o processo de escolarização. Entre os vários problemas enfrentados, o financiamento foi apontado como uma das maiores dificuldades de operacionalização do programa, como também a falta de estratégia adequada para o desenvolvimento de ações geradoras de renda, promotoras de inclusão social das famílias dos egressos do trabalho precoce. Outro ponto importante é a falta de proposta pedagógica de referência para o desenvolvimento das atividades da jornada ampliada, além dos espaços físicos inadequados e insuficientes, e a desarticulação entre a atuação da rede regular de ensino com a jornada ampliada, o que não contribui para o processo de aprendizagem das crianças e dos adolescentes (UNICEF, 2004; OIT, 2001).

Apesar dessas análises, compreende-se, neste artigo, que as atividades socioeducativas e de convivência podem ser valiosos instrumentos de combate ao trabalho infantil, primeiro, por evitarem a ida ao trabalho, e, segundo, porque poderiam contribuir para a ampliação do conhecimento. Na verdade, a escola, aliada às experiências de contra-turno, poderia realizar o que determina a Lei de Diretrizes e Bases (LDB): a educação em turno integral.

Nesse sentido, compreendemos que direitos humanos, cidadania e protagonismo são categorias por excelência para se operacionalizar via extensão. Assim, vários documentos, como a Declaração dos Direitos da Criança (1959), a Convenção dos Direitos da Criança (1989) e o ECA (1990), são instrumentos para atuação na prática extensionista e temáticas possíveis de serem abordadas com os envolvidos.

Concordamos com Neto (2004) quando concebe que a realidade circundante do fazer extensão sempre mantém o convite à necessária conexão entre a crítica, que precisa permanecer no fazer extensionista, com o seu próprio meio material. Entendemos a extensão universitária como uma atividade acadêmica que permite estabelecer parcerias com a sociedade, refletir e produzir conhecimento nas respectivas áreas de atuação e, no âmbito do ensino, conjugar teoria e prática.

Dentro da perspectiva de educação problematizadora e libertadora, todos os sujeitos estão ativamente envolvidos no ato de conhecimento (Silva, 1991; Freire, 1974/1996). É a própria experiência dos educandos que se torna a fonte primária de busca dos temas significativos ou temas geradores que constituirão o conteúdo programático que é sempre o resultado de uma pesquisa no universo experiencial dos próprios educandos, também ativamente envolvidos nessa pesquisa. Não se trata de imposição, e, sim, de uma devolução organizada, sistematizada e acrescentada aos elementos que foram disponibilizados de forma desestruturada.

Como afirma Teixeira (2003), na concepção dialética, esse processo expressa estreita relação entre a teoria e a realidade: a teoria comanda, servindo de guia para a reflexão sobre a realidade, para sua superação e transformação, trazendo luzes, suscitando indagações, indicando e delimitando questões importantes no estudo de um tema. É a realidade concreta, porém, sobre a qual nos debruçamos com o objetivo de transformar, que de fato condiciona o comandante, sempre em um movimento mais vivo, dinâmico e rico que a teoria, necessitando nutrir-se dela para indicar caminhos de transformação.

Desenvolve-se, dessa forma, a concepção de que o ato de conhecer não é um ato isolado, individual, pois, de acordo com Silva, conhecer envolve intercomunicação, intersubjetividade. Essa intercomunicação é mediada pelos objetos a serem conhecidos, 
e é essa intersubjetividade do conhecimento que torna o ato pedagógico um ato dialógico.

De acordo com Tosi (2004), a educação em direitos humanos ou em cidadania vem constituindo, nos últimos anos, um campo específico de pesquisa e de intervenção com objeto, método, bibliografia próprios e um amplo e articulado movimento nacional (e internacional) de educadores. Partilhamos da concepção de Zenaide (2004) de que a educação em direitos humanos gestou-se, portanto, no âmbito da sociedade civil, como uma ação político-pedagógica cujos objetivos estavam voltados para a formação de uma cultura democrática em contraposição às práticas autoritárias.

Por protagonismo juvenil, entendemos aquelas ações cujos atores são os próprios jovens. Embora esse conceito tenha surgido na década de 1990, associado a pessoas nas faixas etárias entre 14 e 25 anos, para efeito da ação extensionista que ora retratamos, aplicamo-lo a crianças e adolescentes entre 07 e 15 anos. Nossas atividades extensionistas tentam empoderar os sujeitos envolvidos para que participem, reflitam sobre suas realidades, tornem-se conscientes e reivindiquem a garantia de seus direitos, através da participação política e de ações objetivas no cotidiano; quiçá se tornem condutores de processos de mudanças e saiam da posição de passividade para a de atores (Iulianelli, 2003). Mas o protagonismo que tentamos trabalhar não é o do ator isolado, para quem todos os demais se voltam, não é a construção de lideranças, mas a participação e a ação coletiva com vistas à cidadania.

Desse modo, a educação popular e os direitos humanos tornam-se, para efeito dessa ação de extensão, áreas parceiras da Psicologia social, uma área da Psicologia que passou por algumas rupturas e avanços em seu decorrer histórico. A partir da década de 60, iniciam-se as críticas à Psicologia social norte-americana como ciência ideológica, que justifica os interesses da classe dominante, que, em uma percepção estreita da vida social, nega a complexidade da realidade social e a dinâmica das relações humanas (Lane, 1995).

Portanto, é a partir dessas críticas que se começa a traçar novos rumos para a Psicologia social, agora em bases do materialismo-histórico, e comprometida com a realidade social. $\mathrm{O}$ surgimento da Psicologia comunitária entre nós aconteceu por volta das décadas de 60 e 70, vinculada ao contexto social, mas como uma prática questionadora dos aspectos políticos opressores e das formas de governo vigentes, e envolvida com a realidade social das populações marginalizadas. Assim, sua atuação nas comunidades parte da problematização da realidade vivida por essas, visando ao desenvolvimento da consciência dos moradores como sujeitos históricos e comunitários, com o desenvolvimento de ações em termos de educação popular (Lane, 1996).

Essa ação extensionista é desenvolvida nos moldes da Psicologia comunitária, concebida como atuação psicológica que tem por objetivo agir com o homem como sujeito ou ator capaz de transformar sua realidade, de uma Psicologia social que não é apenas uma área empírica de atuação que estaria, assim, em ação na área social, mas que é indicativa de um posicionamento epistemológico e ético. "Caso não haja essa diferença, toda psicologia seria social, já que nenhuma refuta a socialização, ou mesmo a interação, como fatores contextuais de seus objetos de análise e de intervenção" (Diehl, Maraschin, \& Tittoni, 2006, p. 409).

\section{As ferramentas usadas na experiência}

A experiência relatada neste artigo referese às atividades desenvolvidas no período 
2008 a 2010 com crianças e adolescentes que participam de dois núcleos do PETI na cidade de João Pessoa. As ações extensionistas iniciaram-se com uma reunião entre coordenação e equipe técnica do PETI e integrantes do Projeto de Extensão (estudantes e professora de Psicologia), na qual se apresentaram de forma mais detalhada os objetivos do projeto e as justificativas para a escolha dos dois núcleos. Havia posições diferentes entre a equipe do PETI e os integrantes do Projeto de Extensão acerca dos critérios da escolha desses núcleos. Foram acordados, no final, os seguintes critérios: um núcleo que já era conhecido e um núcleo com histórico de dificuldades de funcionamento.

A metodologia do projeto de extensão é tomada emprestada da educação popular, e visa a construir conjuntamente o trabalho, considerando-se as experiências expostas pelos envolvidos; consiste nas seguintes etapas: apresentação da proposta a crianças e adolescentes e solicitação da sua autorização. Uma vez aprovada a metodologia, são realizados um acordo de convivência, a escolha das temáticas que serão desenvolvidas, oficinas com os temas acordados, avaliações e reconstrução da proposta, conversas informais com as crianças e adolescentes e encontros com os demais atores a partir das demandas que emergem nas atividades (oficinas ou conversas) com as crianças e adolescentes.

Para desenvolver as atividades de extensão junto às crianças, os extensionistas (estudantes de Psicologia) encontravam-se com elas uma vez por semana nos dois núcleos do PETI e faziam uso da ferramenta oficina, através da qual se trabalha com literatura, escrita, música, filmes, fotografia, gibis, desenhos, o Estatuto da Criança e do Adolescente, conversas em círculos, conversas com pequenos grupos e jogos e brincadeiras.
As oficinas semanais têm formato flexível e são adaptadas ao contexto cotidiano, mas procuram sempre garantir as seguintes etapas: uma dinâmica, apresentação de um tema gerador, problematização, reflexão, identificação de possibilidades de ação e, quando possível, adoção de uma delas. Considerando-se as peculiaridades de cada núcleo, acresce-se um tempo para brincadeiras.

As temáticas tratadas emergem do acordo de convivência (algumas são sugeridas pelas crianças, e outras, pelos extensionistas) e variam de um núcleo para outro (a diferença decorre dos contextos específicos de cada núcleo e das histórias dos atores), mas, de modo geral, são: direitos humanos e cidadania, escola, violência, trabalho infantil, perspectivas de vida e protagonismo, adolescência, diversidade (racial e sexual), cultura, arte, comunidade e história de um dos núcleos.

As ações extensionistas com as crianças e adolescentes demandaram também ações com outros atores: a coordenação PETI, as coordenações dos núcleos, os monitores, as famílias, as escolas, e as Redes Intersetoriais ou Socioassistenciais (saúde, educação e assistência social) localizadas nos bairros onde ficavam os núcleos.

Nas atividades com as coordenações, os monitores, a família, a escola e a rede, fazia-se uso da ferramenta reuniões (de planejamento, articulação e avaliação). No caso das famílias, usou-se ainda a ferramenta visitas domiciliares. A regularidade das reuniões com esses outros atores era ditada pelas demandas que emergiam das atividades com as crianças e adolescentes, e podia ser semanal, mensal ou quinzenal. A exceção eram as visitas às famílias, que também ocorriam semanalmente. 
Tais demandas são principalmente consequência das ações desenvolvidas nas oficinas e, posteriormente, acrescidas das visitas domiciliares. A demanda que emerge já é, de certo modo, uma forma de protagonismo juvenil, pois, ao se tratar determinada temática, as crianças e os adolescentes apresentam aspectos do seu cotidiano e, do seu modo, reivindicam respostas. Essa reivindicação consiste na escuta do coletivo feita pelos extensionistas que é discutida nas reuniões de orientação, quando são analisados os significados e as implicações para os atores que as demandaram. A partir daí, os integrantes do projeto funcionam como mediadores ou articuladores na tentativa de se viabilizarem os encaminhamentos e o retorno para os atores demandantes.

Há também um encontro semanal entre extensionistas e coordenadora do projeto para o planejamento de atividades, avaliações, relato da oficina semanal em cada núcleo, estudos de textos, momentos de problematização, reflexões e orientações.

O nosso papel, como estudantes e professora da Psicologia, consiste em proceder às escutas - uma vez que é essa nossa ferramenta principal de ação - dos vários atores, em especial, das crianças, e problematizar o que escutamos, devolvendo a esses atores o lugar de sujeitos, logo, o de protagonistas de suas histórias. Nessa perspectiva, atuamos como articuladores, informantes de direitos, tentando, junto a essas crianças, ressignificar os sentidos de seus contextos e objetivos de vida, de seus modos de subjetivação, e, a partir de suas reflexões, compreender e transformar o que julgarem necessário para garantir a cidadania e os seus direitos. Já que se faz a escuta do coletivo, discute-se com o coletivo e encaminha-se aquilo que for acordado como ação.

\section{Resultados alcançados: análises e reflexões sobre o vivido}

Ao iniciarmos o projeto, tínhamos como objetivo contribuir para tentar desnaturalizar o trabalho infantil, contribuir para a formação da cidadania de crianças e adolescentes egressas do mundo do trabalho, desenvolver, junto a eles, uma cultura de protagonismo e formar profissionais de Psicologia para atuar em uma perspectiva da Psicologia social. Com o desenrolar do trabalho, conseguimos ver algumas questões que não percebíamos inicialmente, aspectos que nem mesmo estavam entre os objetivos do trabalho.

Percebemos, ao abordar a questão dos direitos da criança e do adolescente, em ambos os núcleos, que eles não conseguem perceber os direitos como algo que Ihes diga respeito e dos quais deveriam ser sujeitos. Até conseguem descrever os direitos das crianças e dos adolescentes, mas reproduzem, em suas falas, um discurso superficial, quase que ensaiado, e que não conseguimos aprofundar. Alguns, com o decorrer do trabalho (e muita repetição do assunto por nossa parte), começam a se ver, ainda que timidamente, como protagonistas dessas temáticas. Mas nem sempre conseguimos trabalhar as suas resistências. Um exemplo disso aconteceu no Núcleo 1, quando pedimos para manter um contato e fazer visitas às escolas em que estudam: mostraram-se contrários, alegando que não seríamos bem recebidos pela direção.

Refletimos acerca do significado disso e pensamos que essa resistência decorria, por um lado, de um aspecto pertinente à sociedade brasileira, aos dilemas relacionados à igualdade no Brasil e ao acesso aos direitos fundamentais, criando-se o que Da Mata (1989) cunhou como o dilema brasileiro; por outro lado, a nossa dificuldade de adentrar a questão decorria de não se sentirem à 
vontade para tal abertura, talvez porque nosso vínculo ainda não estivesse fortalecido.

Com o passar do tempo e com a aproximação entre crianças e adolescentes do PETI e extensionistas, principalmente durante as rodas de conversa, percebemos que esse não era um problema do nosso vínculo com eles. As crianças e os adolescentes não estavam acostumados a serem ouvidos, nem no PETI, nem na escola, e, em vários casos, nem mesmo em casa, um aprendizado, para as crianças, da não cidadania nos moldes analisados por Da Mata (1989). Quando questionadas, muitas vezes davam respostas evasivas (como quando perguntamos para que servia o PETI, e nos responderam que "para aprender coisas novas que não sabíamos antes"), ou mesmo nem respondiam. Lembrando que a participação não era obrigatória nas atividades, tentávamos fazer com que todos participassem, mas quem não quisesse poderia só observar ou fazer outra atividade. Em alguns casos, percebemos que havia, principalmente por parte dos mais velhos, um desejo de mudança daquela realidade, quando um adolescente disse: - Sei que daqui a pouco eu vou sair daqui, mas o que conseguir fica aí pros outros.

Em contrapartida, analisamos que talvez não tenham noção da possibilidade de serem protagonistas, uma vez que o contexto de vida, considerando-se o tempo e o lugar onde residem e se desenvolvem, seja marcado por situações de violência, de exploração e de ausência de políticas públicas que efetivem os seus direitos. Esses outros elementos emergiram ao longo do trabalho em vários aspectos, mas, principalmente, ao se trabalhar a temática escola. Percebemos que representam a escola como um espaço inóspito, permeado por situações de violência (na relação professores e alunos, na relação entre pares e na relação da direção com os alunos) em que não são vistos como capazes de intervir na realidade escolar, de ser protagonistas nesse espaço institucional, o que confirma a concepção de escola como uma instituição disciplinar que, ao negar a relação dialógica e se utilizar da imposição, poda a possibilidade de criação e de autonomia dos seus educandos. "A rigidez dessas posições nega a educação e o conhecimento como um processo de busca" (Freire, 1974/1996, p. 58).

Um exemplo de como a escola poda o protagonismo e impõe certo disciplinamento ou controle é o trecho de uma conversa dos extensionistas com uma professora de uma das escolas visitadas, que disse ter mudado o modo como alguns alunos cortavam o cabelo, e que haviam passado a cobrir suas tatuagens. Vê-se aí claramente uma busca da instituição escolar de moldar seus alunos, de colocá-los em uma forma, o que ocorre não só no aspecto físico mas também no campo das ideias, no qual se vê que, em alguns casos, o questionamento que parte do aluno é entendido como ameaçador, como rebeldia, desconsiderando-se suas experiências.

Após essas análises, percebemos a necessidade de nos aproximarmos da escola por entender que, apesar das dificuldades desta, trata-se de um espaço significativo para as crianças e para os adolescentes, e, além disso, para melhor compreender as problemáticas entre os educandos frequentadores desse núcleo do PETI, de seus professores e diretores. Dessa forma, como já havíamos pedido permissão, resolvemos visitar as escolas e propor reuniões para se discutir a possibilidade de articulação entre estes três espaços: extensão, PETI e escola. Nesta, apresentamos o trabalho desenvolvido no Núcleo 1, além da proposta do $\mathrm{PETI}$, já que muitos não tinham conhecimento nem do trabalho do Núcleo 1, nem da proposta do PETI. Percebemos, portanto, que, para se potencializarem e se prepararem para serem protagonistas, seria necessário que se ampliassem as ações da extensão, o que significava mediar o contato 
entre as crianças e os adolescentes, a escola que frequentavam e o Núcleo 1 do PETI.

A partir dessa aproximação, vimos que o contato entre escola e PETI se restringe ao repasse, pela escola, da frequência escolar, enquanto o contato da escola com o núcleo do PETI se limita ao repasse das notas escolares e ao fornecimento de informações acerca da presença ou ausência das aulas. Mas, apesar desse contato entre escola (através das professoras) e coordenadora do Núcleo 1, a primeira (a escola) não conhece a segunda (o Núcleo 1 do PETI), nem sua história, nem como trabalha, nem o sentido que o núcleo tem para as crianças. O contato é mera ação burocrática.

Os primeiros contatos com a escola foram relevantes, pois notamos que a escola, muitas vezes, culpabiliza seus educandos, sem atentar para como os contextos familiares e as condições de vida deixam de articular essas condições de vida com a socialização e a aprendizagem dos educandos.

Apesar de identificarmos avanços, entendemos que há muito para se trabalhar na perspectiva do protagonismo dos educandos. Por exemplo, na atividade que preparamos juntos para que eles apresentassem a história do Núcleo 1 do PETI à escola - o que infelizmente não aconteceu, porque a escola, embora tenha marcado, não compareceu -, foi preciso muita insistência para que as crianças tivessem voz e fossem realmente protagonistas. Essa falta de voz nos incomodou um pouco, pois estávamos ali para que eles justamente tivessem voz, oportunidade de expressar o que sentiam, o que pensavam sobre aquela realidade em que estão inseridos e sobre suas perspectivas de futuro. Embora a escola não tenha comparecido, esse movimento gerou a produção de um vídeo sobre a história do Núcleo 1. A ideia do vídeo surgiu como resultado da mediação dos extensionistas, na perspectiva de um ditado popular que diz: Se Maomé não vai à montanha, a montanha vai a Maomé. O vídeo serviria para trabalhar com todas as escolas, já que o conjunto das crianças e dos adolescentes do PETI estudava em várias escolas do bairro. O vídeo, pelo menos naquele contexto, gerou o tal protagonismo que se almejava: eles criaram o roteiro, contaram a história, gravaram e trouxeram para o vídeo várias coisas que desejavam dizer para a escola - de como a percebiam, de como eram tratados.

Um outro exemplo é o do Núcleo 2, em que, ao longo do projeto, pudemos perceber alguns avanços, como a questão do protagonismo. Ao iniciarmos o projeto, observamos que a maioria das crianças e adolescentes atendidos naquele núcleo não acreditava poder conseguir alguma mudança efetiva para aquele espaço. Aos poucos, fomos mostrando que, se conseguíssemos nos organizar para fazer a reivindicação coletiva, haveria mais chances de dar certo. De fato, aos poucos, algumas solicitações foram atendidas, como o encontro de adolescentes, a sua participação no Seminário para Construção do Plano Municipal de Combate ao Trabalho Infantil, a conversa e a carta reivindicatória à coordenação, que se tornaram realidade.

A carta surgiu como instrumento para dar voz aos meninos diante da coordenação, para que expressassem como se sentiam naquele ambiente. Percebemos que aquelas janelas quebradas, o ventilador retorcido, a mesa improvisada e a biblioteca de livros sobre o câncer (doada por alguém), entre outras coisas, não incomodavam somente a nós, mas também àqueles meninos e meninas. E que eles queriam que aquilo mudasse, mas não sabiam como, pois já era do conhecimento de todos que já haviam sido feitas reivindicações de melhoras por parte da equipe técnica do programa. Então, em uma conversa, sugerimos que eles próprios se organizassem e escrevessem à coordenação do PETI e 
ao Secretário Municipal responsável pelo assunto. A carta foi ditada por eles e escrita pelos extensionistas. Nela explicitavam-se todas as mudanças que eles queriam ver acontecer naquele núcleo, e providenciamos para que a autoridade responsável, no caso, os coordenadores do programa, fossem receber pessoalmente essa reivindicação e, assim, ouvir o que tinham a dizer.

$\mathrm{O}$ ato de garantir voz ativa a todos fez despertar em alguns deles a percepção de que podem fazer diferente, desde que sejam explicitadas as ferramentas necessárias para isso, e que os educadores tomem aí um papel de facilitadores dessa mudança, não só de educação formal mas também de direitos humanos, cidadania, autonomia e empoderamento.

Vimos também que as crianças e os adolescentes dos dois núcleos do PETI reproduzem várias expressões de violência (verbal, física e psicológica) como formas de expressão que refletem o processo de naturalização da violência e de banalização da vida humana. Diante de tais situações de violência, veem-se impactados e perplexos, sem identificarem saídas para resistir e para transformar tais situações.

Na maioria das vezes, suas falas aparecem eivadas de expressões denotadoras de baixa auto-estima. Acham-se incapazes de responder às indagações que fazemos. E, quando realizam e constroem algo, não consideram bom nem importante o que fizeram, fato que pode ser decorrente do processo de exclusão de que são vítimas e da descrença de mudança vivenciada cotidianamente. Observamos que são sujeitos que se constroem pela negatividade - do não lugar, da não infância, da não adolescência, da não cidadania.

Há entre eles uma constante, mas também naturalizada percepção de que muitas crianças e adolescentes não vivenciam a infância e a adolescência, inclusive eles próprios. Apesar de conseguirem visualizar a necessidade de mudanças, não sabem como fazê-las, e acreditam ser isso difícil, por entenderem que ninguém quer mudar. Uma das expressões dessa naturalização aparece ao se tratar do trabalho infantil. As suas experiências variam da não percepção de si mesmos como trabalhadores infantis ou de não perceberem a exploração de que são vítimas, de desconhecerem que determinadas atividades que desempenham são trabalho, e acham natural realizá-las.

Essa descrença se dá em relação à própria política pública efetivada pelo PETI, ou seja, quanto às limitações do programa. Em uma das atividades realizadas no Núcleo 1, ao se utilizar o filme Crianças Invisíveis como ferramenta facilitadora do diálogo, conversamos sobre o tema trabalho infantil e sobre a importância do PETI para a erradicação. Alguns elementos importantes foram levantados pelas próprias crianças: (a) muitas nem sabiam o que significava a sigla, (b) outras relacionavam o programa estritamente ao recebimento do dinheiro do Programa Bolsa Família, (c) outras continuavam a reproduzir o discurso de que, como os pais, as crianças/os adolescentes também devem trabalhar. Outra consideração significativa foi feita por um dos educandos, quando declarou: - Não há firmeza no PETI. Ele questionou a eficiência do programa que, em sua opinião, precisava de mais ações, controle e supervisão tanto junto aos núcleos quanto junto às famílias, pois, segundo ele, conhecia crianças beneficiadas pela bolsa que continuavam a trabalhar, e outras que recebiam e não frequentavam as ações socioeducativas.

Percebemos ainda que há diferenças nos modos de organização do trabalho nos dois núcleos do PETI. O Núcleo 1, com o formato de ONG, prima pelo acompanhamento 
dos sujeitos, da escolaridade, da realização diária das tarefas escolares, da promoção constante do acesso a conteúdos considerados complementares à formação, da cobrança e do acompanhamento junto aos pais e da preocupação com o atendimento de certas necessidades das famílias como forma de melhorar as condições de vida das crianças. O Núcleo 2, coordenado pela própria OG gestora do programa, não oferece o mesmo acompanhamento às crianças e adolescentes, nem da sua escolaridade, nem de suas famílias. E ainda têm uma trajetória de dificuldades desde a coordenação do espaço até a rotatividade e a ausência dos educadores, chegando à não efetivação de promessas de lazer. Diante de tal situação, as crianças e os adolescentes expressam constantemente sentimentos de revolta e de descrédito.

Outras articulações foram realizadas também a partir das demandas surgidas nas atividades com as crianças e os adolescentes, como a aproximação com as famílias através das visitas domiciliares, o que nos proporcionou melhor compreensão do espaço de formação e dos contextos de subjetivação de tais sujeitos.

A articulação com as famílias ocorreu a partir de demandas específicas, pois, devido ao número de educandos e ao curto tempo de trabalho, tornou-se necessário priorizar alguns casos, como: Saúde Mental, alcoolismo, violência doméstica, violação dos direitos da criança, negligência e abuso sexual. O decorrer das visitas permitiu aos extensionistas conhecer as diversas constituições familiares dos educandos do núcleo, além das diversas situações que revelam várias formas de violência, inclusive, da violência estrutural.

Mas, apesar das dificuldades a partir das ações extensionistas, há lampejos e sinais de mudança, de perspectivas de futuro, de protagonismo (entre outros, nos exemplos já citados na construção do filme, na construção da carta e na participação no seminário municipal e no encontro de adolescentes do PETI). As mudanças aparecem tanto nas atividades com as crianças e os adolescentes quanto com os educadores, a família, a coordenação dos núcleos, a coordenação do PETI e as Redes Intersetoriais ou Socioassistenciais nos territórios onde se localizam os dois núcleos. São exemplos dessas mudanças a criação de espaços coletivos para planejamento das atividades entre extensionistas e monitores do PETI, a articulação entre o PETI, o Centro de Cidadania, o Centro de Referência em Assistência Social (CRAS) e a UFPB, a mobilização junto ao Fórum Estadual de Erradicação do Trabalho Infantil e Defesa do Adolescente Trabalhador (FEPETI) e o estabelecimento de parcerias com instituições do Sistema S (SENAC, SENAT) para elaboração e execução de projeto de formação e inserção de egressos do PETI nos programas de aprendizagem.

Um outro exemplo foi uma ação articulada junto à Rede Intersetorial ou Socioassistencial para garantir os direitos de uma das crianças. Essa ação envolveu um ano de trabalho, com reuniões quinzenais ou mensais nas quais cada instituição desempenhava uma ação dentro do que está prescrito como sua função na via efetivação de acesso dos cidadãos às políticas públicas, quer para a criança, quer para a família. O resultado foi satisfatório, tanto pela garantia do direito à criança e à família, como pelo fato de o Projeto de Extensão ter atuado como mediador e, principalmente, por conseguir mostrar a viabilidade de um trabalho em rede.

\section{Considerações finais}

Esses questionamentos sobre a eficiência do PETI, feitos pelas próprias crianças e adolescentes, salientam as limitações do 
programa, que, apesar de ter conseguido diminuir as estatísticas do trabalho infantil, necessita de avanços tanto no que diz respeito à sistemática das ações socioeducativas e à melhora da qualificação dos monitores como também às ações mais próximas com as famílias, pois muitos continuam reproduzindo a cultura de que crianças e adolescentes devem trabalhar para evitar a marginalidade e a vagabundagem.

Outra ação que necessita ser pensada de modo mais efetivo pelo programa e outrora debatido junto às crianças dos dois núcleos do PETI é a geração de renda pelos familiares. Constatamos que muitas famílias não têm emprego e vivem da renda oriunda da bolsa recebida no contexto do Programa Bolsa Família. Como, muitas vezes, essa renda não é suficiente, acaba-se recorrendo ao trabalho infantil, o que confirma os dados da pesquisa de Rua, quando se evidencia a falta de ações promovedoras da inclusão social e da autonomia das famílias dos egressos do trabalho precoce.

No entanto, é preciso considerar a diversidade dos contextos familiares, diferenciando-os das representações ideais ou hegemônicas, como uma resposta a diferentes condições de vida e de contextos sociais, o que implica outras formas de resolução dos conflitos e problemáticas cotidianas; no entanto, isso não quer dizer que as famílias não precisam ser responsabilizadas pela conservação e pela promoção dos direitos dos seus componentes, mas que, devido às dificuldades enfrentadas, precisam de apoio para intervir nessas questões.

As ações desenvolvidas nesse Projeto de Extensão não constituíram uma intervenção fácil devido às condições objetivas de vida desses sujeitos. A exclusão de que são vítimas engendra processos de subjetivação que retira deles a possibilidade de se perceberem como sujeitos de direitos, o que os faz naturalizar a violência e não acreditar em mudanças. Em decorrência desses fatores, aliados aos institucionais, tanto do PETI, da gestão municipal, como da universidade, também houve dificuldades para se atingir integralmente todos os objetivos, como, por exemplo, o trabalho com as escolas.

Quando iniciamos esse projeto, embora já tivéssemos certo know how da temática do trabalho infantil, não tínhamos certezas nem expectativa de atingir quaisquer resultados ou produtos. Conhecíamos também as dificuldades metodológicas que enfrentaríamos, pois a Psicologia tem, em sua construção histórica, ranços oriundos de perspectivas ou de modelos de atuação individualizante. Isso dificulta o acompanhamento das novas singularidades decorrentes das mudanças e os processos de integração dos diversos protagonistas pelo psicólogo, o que requer o seu deslocamento nos diversos espaços por onde transita, sejam familiares, sejam institucionais (Gonzáles-Rey, 2001).

A experiência de extensão universitária nos possibilitou a aproximação e a reflexão de uma realidade social que, por mais que a conhecêssemos, tomou outras dimensões quando ocorreu uma intervenção prática. Nesse contexto, permitiu-nos avançar, no plano teórico, para a construção de conhecimento e de desenvolvimento de instrumentais de análise e atuação. Além disso, deu-nos a oportunidade de vivenciar as dificuldades do que seja trabalhar com instituições e setores ligados às políticas públicas, com toda a teia burocrática que tecem, que contribuiu muitas vezes para emperrar nosso trabalho. Discordamos em alguns pontos da instituição PETI (tanto da proposta de programa e de políticas públicas quanto da gestão local), mas acreditamos que assim podemos crescer como profissionais, com discussões, com trocas de conhecimento e de experiências. 
Encarar a realidade foi muito importante para o nosso avanço como estudantes e futuros psicólogos, e deu-nos realmente a ideia de uma psicologia ampliada, que sai da sala para a comunidade, que tenta atender as novas necessidades sociais, criando outras formas de olhar para a questão, redimensionando-a. Por se tratar de uma ação desafiadora como prática psicológica, encontramos muitas dificuldades nesse percurso, que se instalaram tanto no âmbito profissional da Psicologia, cujas práticas têm estado mais a serviço da elite (Bock, 2003) e menos envolvidas com as camadas sociais excluídas socialmente, quanto no âmbito de uma forma passiva de apreensão do mundo, ideologicamente cristalizada nesses sujeitos.
O que tornou o trabalho mais interessante foi o contato com crianças, sujeitos ainda cheios de imaginação e desejos, e, mesmo quando suas brutais realidades não as deixavam desfrutar do fato de serem crianças, de gozarem de seus direitos como tais, conseguíamos visualizar as poucas esperanças ainda alimentadas por elas quando falavam do futuro e da importância do estudo. De atividades pensadas a atividades inventadas a partir das demandas, fomos ganhando confiança e intimidade, construindo laços e recebendo afetos, bons e maus. 


\section{Maria de Fátima Pereira Alberto}

Doutora em Sociologia pela Universidade Federal de Pernambuco. Professora Associada do Departamento de Psicologia e do Programa de Pós-graduação em Psicologia Social da Universidade Federal da Paraíba, Paraíba, PB- Brasil, pesquisadora do CNPq.

E-mail: jfalberto@uol.com.br

\section{Romanan Silva Borges}

Graduação em psicologia pela Universidade Federal da Paraíba, Paraíba, PB - Brasil.

E-mail: romanan_borges@hotmail.com

\section{Manuella Castelo Branco Pessoa}

Mestranda Programa de Pós-graduação em Psicologia Social da UFPB, Paraíba, PB- Brasil.

E-mail: manucastelobranco2@gmail.com

\section{Juliana Mendes Lopes de Sousa}

Graduação em Psicologia pela Universidade Federal da Paraíba, Paraíba, PB - Brasil.

E-mail: juliana_mendeslopes@yahoo.com.br

\section{Pedro Felipe Moura de Araújo}

Graduação em Psicologia pela Universidade Federal da Paraíba. Psicólogo no Centro Cultural Piollin, Paraíba PB - Brasil.

E-mail: peehfe@gmail.com

\section{Rodrigo de Oliveira Feitosa Vaz}

Graduado em Psicologia pela Universidade Federal da Paraíba. Psicólogo do Complexo Psiquiátrico Juliano

Moreira, Paraíba - PB - Brasil.

E-mail: rodrigofeitosa18@hotmail.com

\section{Felipe Medeiros de Farias}

Graduando em Psicologia pela Universidade Federal da Paraíba, Paraíba - PB - Brasil.

E-mail: felipemedeirosxy@hotmail.com

\section{Leonardo José de Alencar Mendes}

Graduado em Psicologia pela Universidade Federal da Paraíba, Paraíba - PB - Brasil.

E-mail: leo_brak@hotmail.com

\section{Endereço para envio de correspondência:}

Rua Sebastião Interaminense, Ed. Porto Lugano, no 369, Apto 202

Bessa, João Pessoa - PB - Brasil. CEP: 58037-770

Recebido 22/4/2010, 1a Reformulação 1/11/2011, Aprovado 10/1/2012. 
Acción contra la prosituición infantil (1996). Los niños y el trabajo, Genebra, 2(11), 3-6.

Alberto, M. F. P., Almeida, D. R., Dória, L. C., Guedes, P. C., Sousa, T. R. de, \& França, L. P. de. (2008). O papel do psicólogo e das entidades junto a crianças e adolescentes em situação de risco. Psicologia: Ciência e Profissão, 28 (1), 558-573.

Alberto, M. F. P. (2002). A dimensão subjetiva do trabalho precoce de meninos e meninas em condição de rua em João Pessoa $(P B)$. Tese de doutorado. Programa de Pós-Graduação em Sociologia, Universidade Federal de Pernambuco, Recife, PE.

Bock, A. M. B. (2003). Psicologia e sua ideologia: 40 anos de compromisso com as elites. In A. M. B. Bock. (Org.), Psicologia e compromisso social. São Paulo: Cortez.

Brasil. Ministério da Previdência e Assistência Social. (2002). Programa de erradicação ao trabalho infantil: manual de orientações. Brasília, DF: Autor

Brasil. Ministério da Previdência e Assistência Social. (2005) Portaria GM/MDS $n^{\circ} 666$ de 28 de dezembro de 2005. Disciplina a integração entre Bolsa Família e o Programa de Erradicação do Trabalho Infantil. Recuperado em 10 de abril de 2008 de http://www.mds.gov.br

Buonfiglio, M. C. (2004). Políticas públicas em questão: o plano de qualificação do trabalhador. João Pessoa, PB: Manufatura.

Campos, M. S. (1999). Trabalho infantil, desafio à sociedade: avaliação do programa de erradicação do trabalho infantil no período de 1996-97. Brasília, DF: Secretaria de Estado de Assistência Social, MPAS.

Da Matta, R. (1989). Carnavais, malandros e heróis. Rio de Janeiro: Guanabara.

Dantas, N. M. R. (2006). O monitor do PETI: o leigo educador ou o educador leigo? Monografia, Departamento de Psicologia. Universidade Federal da Paraíba, João Pessoa, PB.

Diehl, R., Maraschin, C., \& Tittoni, J (2006). Ferramentas para uma psicologia social. Psicologia em Estudo, 11(2), 407-415.

Domingos, M. S. S. R., Silva, R. M. P., \& Teixeira, D. M. (2003). Impactos do PETI na realidade de trabalho de crianças e adolescentes de João Pessoa. In M. F. P. Alberto, (Org.), Crianças e adolescentes que trabalham: cenas de uma realidade negada (pp. 277-288). João Pessoa, PB: UFPB.

Freire, P. (1996). Pedagogia do oprimido. Rio de Janeiro: Paz e Terra (17a ed.) (Trabalho original publicado em 1974).

Fundo das Nações Unidas para a Infância. (UNICEF). (2004). Análise situacional do programa de erradicação do trabalho infantil - PETI. Brasília, DF: UNICEF.

González-Rey, F. L. (2001). O enfoque histórico-cultural e seu sentido para a psicologia clínica: uma reflexão. In A. M. B. Bock, M. G. M. Gonçalves \& O. Furtado (Orgs.), Psicologia sócio-histórica: uma perspectiva crítica em Psicologia (pp.193214). São Paulo: Cortez.

Instituto Econômico de Pesquisa Aplicada - IPEA. (2008). PNAD 2007 - primeiras análises: mercado de trabalho infantil, 2, 10. Recuperado 10 abril, 2008, de http://www.ipea.gov.br/sites/

Iulianelli, S (2003). Juventude: construindo processos: o protagonismo juvenil. In S. Iulianelli, \& P. C. P. Fraga, (Org.), Jovens em tempo real (pp. 55-75). Rio de Janeiro: DP\&A.

Lane, S. T. M. (1995). Avanços da psicologia social na América Latina. In S. T. M. Lane, \& B. B. Sawaia, (Orgs.), Novas veredas em psicologia social. São Paulo: EDUC; Brasiliense.

Lane, S. T. M. (1996). Parar para pensar... e depois fazer. Psicologia e Sociedade, 8(1), 3-15

Neto, J. F. M. (2004). Extensão universitária, autogestão e educação popular. João Pessoa, PB: UFPB.

Organização Internacional do Trabalho (2001). Combatendo o trabalho infantil: guia para educadores. Recuperado em 13 março, 2005, de http://www.ilo.org/public/.

Pinheiro, D. A. A. (2008). A jornada ampliada do PETI em Manaus: a perspectiva dos educandos e monitores. Dissertação de mestrado. Programa de Pós-Graduação em Psicologia Social, Universidade Federal da Paraíba, João Pessoa, PB.

Rua, M. G. (2007). Avaliação da integração do Programa de Erradicação do Trabalho Infantil (PETI) ao Programa BolsaFamília (PBF). Brasília, DF: Fórum Nacional de Prevenção e Erradicação do Trabalho Infantil - FNPETI.

Silva, M. O. da S. (1991). Refletindo a pesquisa participante (2a ed). São Paulo: Cortez.

Silva, M. S. V. L., \& Melo, T. K. S. (2003). O programa de erradicação do trabalho infantil segundo o olhar de seus usuários. In M. F. P. Alberto, (Org.), Crianças e adolescentes que trabalham: cenas de uma realidade negada (pp. 289-296). João Pessoa, PB: UFPB.

Teixeira, D. M. (2003). Oficina temática: uma opção metodológica no curso de formação de agentes sociais na área do trabalho infanto-juvenil. In M. F. P. Alberto, (Org.), Crianças e adolescentes que trabalham: cenas de uma realidade negada (pp. 45-53). João Pessoa, PB: UFPB.

Tosi, G. (2004). A universidade e a educação em direitos humanos. In M. F. P. Alberto, (Org.), Trabalho infanto-juvenil e direitos humanos (pp. 77-95). João Pessoa, PB: UFPB.

Zenaide, M. N. T. (2004). Educação em direitos humanos. In M. F. P. Alberto, (Org.), Trabalho infanto-juvenil e direitos humanos (pp. 97-104). João Pessoa, PB: UFPB. 